\title{
Factors associated with tuberculosis treatment completion by Gender during 2014 - 2016 in Kampala, Uganda: A retrospective descriptive study
}

Etwom Alfred ( $\square$ aetwom@gmail.com )

Republic of Uganda Ministry of Health https://orcid.org/0000-0001-8956-8994

Moorine Penninah Sekadde

Ministry of Health

Aldomoro Burua

Ministry of Health

Frank Mugabe

Ministry of Health

Ismael Kawooya

Makerere University College of Health Sciences

Hannock Tweya

University of Northern lowa

Research article

Keywords: tuberculosis treatment, gender

Posted Date: January 3rd, 2020

DOl: https://doi.org/10.21203/rs.2.20002/v1

License: (9) (i) This work is licensed under a Creative Commons Attribution 4.0 International License.

Read Full License 


\section{Abstract}

\section{Background}

To date, limited number of studies have explored the effect of gender in treatment outcomes in Uganda. No data on disaggregated treatment outcomes and influential factors by gender has been comprehensive compiled by the existing studies.

\section{Objective}

To determine the gender differences in TB patients treatment outcomes between 2014 and 2016 in Kampala in order to inform national policy and provide targeted interventions.

Methods

A retrospective cohort study using routine data of all eligible individuals who were initiated on first-line TB therapy between 2014 and 2016. De-identified data was obtained from all the Kampala divisions electronic TB registers, cleaned and analysed using STATA version 13.

Results

Of the 18,855 patients started on treatment during the study period, only 17,461 were included in the final analysis. Males were more likely to be 35 years or older, received DOT at facility yet females were more likely to be new patients. In addition, males were more likely to be pulmonary bacteriologically confirmed than females (OR $1.0895 \% \mathrm{Cl} 1.00$ - 1.17). Successful treatment completion and ART uptake were similar by gender. Of all outcomes, $83 \%$ were treatment successfully, $11 \%$ died, $1 \%$ treatment failed treatment and $5 \%$ got lost to follow-up. Compared to females, males were more likely to be lost from TB care and die compared to females.

Conclusion

Among TB patients in Kampala from 2014 to 2016, we found evidence that successful treatment completion is not influenced by gender. However other factors that may be associated with successful TB treatment completion include age, disease classification, HIV status and type of patient.

\section{Background}

Tuberculosis (TB) is an airborne-transmitted infectious disease with high morbidity and mortality around the world. According to the 2017 global TB report, an estimated 10.4 million people fell ill with TB in the previous year (Global TB report 2017). TB burden is more pronounced in African countries probably due to high HIV prevalence and so the continent accounts for about $25 \%$ of TB cases (Global TB report, 2017). In the above report, approximately 1.9 times males aged 15 years and old were diagnosed with TB worldwide compared to females in 2016. 
While previous studies have reported gender disparities in health seeking behavior and treatment outcomes (Chandrashekhar T Sreeramareddy et al, 2014), late access to TB treatment and adherence coupled with health system challenges often lead to poor treatment outcomes and high mortality as well (Abhijit Mukherjee et al, 2012). Differences in health literacy, sociocultural factors, provider or systemlevel barriers, low degree TB suspicion index by health provider, the number and types of providers seen before TB diagnosis have been reported as contributing to the differences in TB clinical status at presentation, notification rates and TB treatment outcomes by gender (Dodor et al, 2005). These factors can be summarized into three broad themes: TB-related knowledge, education gender roles and status in the family. Surprisingly, despite facing more socioeconomic and cultural adversities women are less likely to die, fail or default from TB treatment compared to men (Jimenez-Corona ME et al, 2006).

To date, a limited number of investigators have explored the factors associated with treatment completion by gender especially within a single cohort in Uganda. In addition, most studies of gender and TB have been conducted in high resource settings, and the extent to which differences in management by gender persist in low-resource contexts is not clear.

Uganda ranked among world's 30 countries with a high TB/HIV burden, has the TB prevalence of about 253 per 100,000 population and the average ratio of male to female in bacteriologically confirmed TB cases as 4.0 (Uganda TB prevalence survey, 2015). The country has an annual average TB treatment success rate of $75 \%$ while Kampala's has been about $68 \%$ which is below the $85 \%$ target.

Factors associated with loss to follow up from anti-TB treatment are old age (De Albuquerque et al. 2007), being male, and low education level (Tissera 2003). Migration for work, perception that TB is incurable and poor knowledge about TB also increase the risk for loss to follow up (Vijay et al. 2003), as do low income and poor attitude of heath care workers (Dodor \& Afenyadu 2005; Holtz et al. 2006). Thus knowledge of patient factors associated with unfavourable treatment outcomes is crucial in developing strategies to improve treatment success rates. We investigated factors associated with treatment completion by gender in Kampala, Uganda.

\section{Methods}

\section{Study design}

This was a retrospective study of bacteriologically or clinically proven TB patients started on anti-TB treatment in 63 health facilities in Kampala in Uganda, January 2014 to December 2016. The 63 health facilities included 2 national referral hospitals, 2 regional referral hospitals, 15 general hospitals, 7 health centre IVs, 23 health centre IIIs, 4 health centre IIs and 10 clinics.

\section{Settings}

\section{General settings}


Kampala is Uganda's capital city with a population of $1,583,000$ people and $91 \%$ of the population stay in urban setting. TB control is supervised by the National TB and Leprosy control Program (NTLP) under Ministry of Health. TB diagnosis and treatment services are integrated into the general health care.

TB diagnosis was based on clinical examination, sputum smear microscopy, chest radiography, GeneXpert ${ }^{\circledR}$, and other investigations as appropriate for extra-pulmonary disease. Providers documented patient's demographic and clinical information in a unit TB registers at treatment initiation and drug dispensing information during treatment follow-up. TB patients were initiated on treatment on in-and outpatient's basis. Treatment consisted of a 2-month intensive phase of Rifampicin, Isoniazid, Pyrazinamide and Ethambutol followed by a 4-month continuation phase of Rifampicin and Isoniazid. Patients were scheduled to pick-up TB drugs at bi-weekly in intensive and monthly in continuation phases respectively. Upon completion of the treatment and the necessary follow up investigation, treatment outcomes were assigned according to the WHO's definition. Certificates were given to patients who successfully completed the treatment.

\section{Study population}

All TB patients diagnosed between January 2014 to December 2016 in Kampala were included in the study. However patients diagnosed and initiated on treatment from outside Kampala excluded because it was difficult to gather their complete records. Also non-transferred out patients whose final treatment outcomes could not established were excluded from the study as health workers did not know what happened to them.

\section{Data management and Analysis}

Data was extracted from TB electronic registers of 63 health facilities into STATA version 13. Independent variables were chosen from the registers based on plausibility and previous evidence of association from the literature. Data was checked for consistency, completeness, clarity and accuracy before analysis.

Descriptive statistics included calculating the mean, median and mean age, and proportions of different patient characteristics. Comparative bivariate tests Pearson's chi-square and two sample t-test was used for categorical variables to evaluate associations between dependent and independent variables. All variables with a p-value less or equal to 0.20 at the bi-variable analysis stage were included in a logistic regression to identify factors associated with treatment completion by gender.

In addition, collinearity and confounding elements among factors were checked and removed from the final model. The association was considered significant between predictor variables with the dependent variable if the $p$-value was $<0.05$. Odds ratios and their corresponding $95 \%$ confidence interval $(\mathrm{Cl})$ were reported as the measures of association.

\section{Ethical considerations}


Prior to data collection, ethical approval was obtained from the School of Medicine Research and Ethics Committee - Makerere University College of Health Sciences and Uganda National Council of Science and Technology. No patient identifier information was collected as a way of maintaining confidentiality.

\section{Aim Of The Study}

To explore factors associated with treatment completion among TB patients initiated on first line TB therapy between 2014 and 2016 in Kampala city (Uganda). The study will inform national policy and provide targeted gender based interventions aimed at reducing disproportionate TB burden in the country.

\section{Specific Objectives}

1. To calculate proportions of TB patients who successfully completed treatment by gender of TB patients initiated on first-line TB therapy during 2014- 2016 in 63 health facilities in Kampala.

2. To assess gender related factors affecting TB treatment completion of patients initiated on first line TB therapy during 2014- 2016 in 63 health facilities in Kampala.

\section{Results}

Between 2014 and 2016, 18,855 TB patients were registered for treatment in the 63 health facilities in Kampala. A total of 1394 patients were excluded from the study; because 1,111 (6\%) started treatment at facilities outside Kampala and 283 (2\%) had no treatment outcomes. The remaining 17,461 were included in the study for analysis. Of these, 10,877 (62\%) were males. The median age at treatment registration was 30 years (interquartile range (IQR) 24 - 40) with 35\% of the patients aged 35 years and above.

While patients were proportionately distributed by level of care and gender, about $65 \%$ of the patients were treated from government owned health facilities. While the rest of patients were distributed in the facilities located in the 5 administrative divisions of Kampala, 39.1\% were treated from Mulago which is the national referral hospital for the country.

Table 1 shows distribution of baseline characteristics by gender. Males were more likely to be 35 years or older, received DOT at facility yet females were more likely to be new patients. In addition, males were more likely to be pulmonary bacteriologically confirmed than females (OR 1.08 95\% Cl 1.00 - 1.17).

All patients were tested for HIV, $48.9 \%$ of them were found to be TB/HIV co-infected and $92.7 \%$ of those co-infected were initiated on ART at the beginning of TB treatment. However males were less likely to be diagnosed HIV positive and being new TB patients at diagnosis than females (HIV positive: OR 0.70 95\% Cl 0.65 - 0.74; New TB patients: OR 0.58 95\% Cl 0.49-0.68).

Successful treatment completion and ART uptake were similar by gender. Of all outcomes, $83 \%$ were treatment successfully, $11 \%$ died, $1 \%$ treatment failed treatment and $5 \%$ got lost to follow-up. Compared to females, males were more likely to be lost from TB care and die compared to females $(p<0.001)$. 
A logistic regression model (see table 2) showed that clinically and extra-pulmonary diagnosed patients were likely to successfully complete treatment compared to bacteriologically confirmed patients for both males and females. Across both gender, new patients were more likely to successfully complete treatment compared to their previously treated patients. Also between both males and females, having negative HIV status was significantly associated with successful treatment completion compared to having positive HIV status.

On the other hand, young age among males was found to be significantly associated successful treatment completion compared to female counterparts. Compared to males aged between $0-14$ years old, age categories between 5 - 14 years (Adj. OR 2.02 95\% Cl 1.26 - 3.24), 15 - 24 years (Adj. OR 1.91 $95 \% \mathrm{Cl} 1.34-2.71$ ) and $25-34$ years (Adj. OR 1.39 95\% Cl $1.00-1.94$ ) supported above finding.

Patients treated from general hospitals, health centres IVs and IIIs were significantly more likely to successfully complete treatment across gender compared their counterparts treated from the 2 national referral hospitals. Furthermore, female patients treated from private clinics had a higher odds (Adj. OR $2.0495 \% \mathrm{Cl} 1.04-4.01$ ) of compared to their counterparts at the national referral hospitals.

\section{Discussion}

Among TB patients in Kampala from 2014 to 2016, we found evidence that successful treatment completion is not influenced by gender. Although impact of gender on treatment outcomes of TB patients has been evaluated in previous studies, has revealed inconsistent results. This finding is consistent with studies carried out in Brazil and Egypt (Kamel Ml, et al 2003).

However in those with unfavorable treatment outcomes, more males got lost to follow up compared to females. The similarities observed in our setting were consistent with the international literature (J. $-Y$ Yeng et al, 2012, K. Dale et al, 2015). Overall, these observations are consistent with the hypothesis that under normal circumstances, males and females have the same chance of successfully completing TB treatment in Kampala.

We found that while more females were TB/HIV co-infected and new on TB treatment, males were more likely to be pulmonary bacteriologically confirmed compared to counterparts. These findings are consistent with other studies carried out in cities and urban settings like Kampala (Abhijit Mukherjee, et al 2012). Strengthening health provider-initiated TB screening capacity using the NTLP recommended job aid may provide opportunity for early TB case finding and prompt treatment initiation

On the other hand, socioeconomic barriers may also exist and hinder healthcare-seeking behavior in women. Therefore under-diagnosis of TB in women is a pivotal issue in TB management and should be carefully evaluated in Uganda and other under developed countries. Regarding clinical presentations, females were found to be less symptomatic as compared with male patients just like in the Uganda prevalence survey report. Also a national tuberculosis survey in Bangladesh described a lower awareness of symptoms among female TB patients (Hamid Salim MA, 2004). The absence of respiratory and 
constitutional symptoms may lead to a delay in seeking medical assistance. Less advanced radiographic findings also make it less likely that health workers will suspect pulmonary TB. Although details about delays in diagnosis were not collected in the present study, all of these factors may contribute to a delayed or low diagnosis of bacteriologically confirmed TB in women as suggested by this study.

Mortality in TB patients is mainly affected by age, disease classification, ART uptake and health facility level of care. This means that younger, clinically diagnosed or extra-pulmonary who are treated from lower levels of care are prone to death. Providing ART to TB/HIV co-infected immediately during TB treatment reduces the risk of dying or getting lost to follow up. These findings disclose the differences between male and female TB patients with regards to clinical characteristics and possible impact on treatment outcomes. We did not divide deaths as being TB related or non-TB related due to the difficulties in evaluating the impact of TB on mortality. All-cause mortality is more objective and applicable in clinical practice.

\section{Conclusions}

Furthermore the study was performed in an under developed country with a high HIV prevalence, and ART initiation may have not been prompt and routine among all TB/HIV co-infected patients. This may limit the ability of our findings to be applied to high to middle-income countries or low HIV endemic areas.

Since getting lost to follow up during TB treatment was influenced by male gender and patient type, instituting gender-specific strategies in TB management like getting family or community support for male patients could reduce unfavourable treatment outcomes. Integration of TB and HIV services especially for counselling may also allow for efficient delivery of important information to patients. Further studies focusing on immunological characteristics are also warranted to elucidate gender related factors other than socio-cultural and clinical factors.

There are several limitations to this study. The duration of presenting symptoms or extent of disease before diagnosis was not recorded in our patients, yet this may influence outcomes. Study hospitals included a national referral hospital where patients with a higher severity or co-morbidities may have been included.

We also acknowledge that interpretation of the strength of our findings should be considered in the context of multiple statistical comparisons, and that the potential for type- 1 errors exists. The differences that we reported were generally small-to-moderate in magnitude, and caution should be taken in ascribing too much importance to any single finding.

\section{Abbreviations}

TB Tuberculosis

OR Odds Ratio 
ART Antiretroviral Therapy

HIV Human Immunodeficiency Virus

NTLP National TB and Leprosy control Program

WHO World Health Organization

$\mathrm{Cl} \quad$ Confidence Interval

DOT Directly Observed Therapy

\section{Declarations}

\section{Ethics approval and consent to participate:}

Ethics approval was obtained from the Makerere University College of Health sciences research ethics review board. As secondary data were used, the need for informed patient consent was waived.

\section{Consent for publication}

Not applicable

\section{Availability of data and material}

The data collected and used for the study is available and there is no objection from Uganda Ministry of Health to share this data

\section{Competing interests}

Authors declare no competing interest

\section{Funding}

Not applicable

\section{Authors' contributions}

(EA, MPS, AB, FM, IK \& HT are initials e.g. Hannock Tweya $\rightarrow \mathrm{HT}$ )

EA conceived the study; EA designed the study protocol; EA, MPS, AB, FM and HT implemented the study. EA and HT carried out analysis and interpretation of these data. EA and HT drafted the manuscript; MPS, $A B, F M$ \& IK critically revised the manuscript for intellectual content. All authors read and approved the final manuscript. EA and HT are guarantors of the paper.

\section{Acknowledgements}


We are grateful to the patients, the clinic personnel and the data personnel of Kampala Capital City Authority for their vital contribution to this study.

\section{References}

1. Abhijit Mukherjee, et al Gender differences in notification rates, clinical forms and treatment outcome of tuberculosis patients under the RNTCP, 2012.

2. Chakraborty AK. Epidemiology of tuberculosis: Current status in India. Indian J Med Res 2004; 120:248-76.

3. Chandrashekhar T Sreeramareddy, et al Delays in diagnosis and treatment of pulmonary tuberculosis in India: a systematic review. Yang (2014) Barriers and Delays in Tuberculosis Diagnosis and Treatment Services: Does Gender Matter?

4. De Albuquerque MdeF, Ximenes RA, Lucena-Silva N et al. (2007) Factors associated with treatment failure, dropout, and death in a cohort of tuberculosis patients in Recife, Pernambuco State, Brazil. Cadernos de Sau' de Pu' blica 23, 1573-1582.

5. Dereje, H., Woldaregay, E. A., Mulugeta B. Childhood tuberculosis and its treatment outcomes in Addis Ababa: 5 -year's retrospective study. BMC Pediatr. 2014; 14(61).

6. Dodd, P. J., Yuen, C. M., Sismanidis, C., Seddon, J. A., \& Jenkins HE. The global burden of tuberculosis mortality in children: a mathematical modelling study. Lancet Glob Heal. 2017; e898-906.

7. Dodor EA \& Afenyadu GY (2005) Factors associated with tuberculosis treatment default and completion at the Effia-Nkwanta Regional Hospital in Ghana. Transactions of the Royal Society of Tropical Medicine and Hygiene 99, 827-832.

8. Enane, L. A., Lowenthal, E. D., Arscott-Mills, T., Mathare, M., Smallcomb, L. S., Kgwaadira, B., Steenhoff AP. Loss to follow-up among adolescents with tuberculosis in Gabarone, Botswana. Int J Tuberc Lung Dis. 2016; 1320-5.

9. Engelbrecht, M. C., Kigozi, N. G., Chikobvu, P., Botha S. Unsuccessful TB treatment outcomes with a focus on HIV co-infected cases: a cross-sectional retrospective record review in a high-burdened province of South Africa. BMC Heal Serv Res. 2017;

10. Forssbohm M, ZwahlenM, Loddenkempe R, Rieder HL. Demographic characteristics of patients with extrapulmonary tuberculosis in Germany. Eur Respir J 2008;31:99-105

11. Gender differences in notification rates, clinical forms and treatment outcome of tuberculosis patients under the RNTCP.

12. Gender differences in tuberculosis diagnosis, treatment and outcomes in Victoria, Australia, 20022015.

13. Hamid Salim MA, Declercq E, Van Deun A, Saki KA. Gender differences in tuberculosis: a prevalence survey done in bangladesh. Int JTuberc Lung Dis 2004.

14. Holtz TH, Lancaster J, Laserson KF et al. (2006) Risk factors associated with default from multidrugresistant tuberculosis treatment, South Africa, 1999-2001. The International Journal of Tuberculosis 
and Lung Disease 10, 649-655.

15. Jimenez-Corona ME, Garcia-Garcia L, DeRiemer K, Ferreyra-Reyes L, Bobadilla-del-Valle M, CanoArellano B, et al. Gender differentials of pulmonary tuberculosis transmission and reactivation in an endemic area. Thorax. 2006

16. Kamel MI, Rashed S, Foda N, Mohie A, Loutfy M. Gender differences in health care utilization and outcome of respiratory tuberculosis in Alexandria. East Mediterr Health J 2003.

17. Kiwanuka JP. Tuberculosis in children at Mbarara University Teaching Hospital Uganda: diagnosis and outcome of treatment. Afr Heal Sci, 2002; 82-8.

18. Nabukeera- Barungi, N., Wilmshurst, J., Rudzani, M., \& Nuttall J. Presentation and outcome of tuberculous meningitis among children: experiences from a tertiary children's hospital. Afr Heal Sci. 2014.

19. National Tuberculosis and Leprosy Program. Annual report 2016/2017. 2017.

20. National Tuberculosis and Leprosy Program. The Uganda national population based Tuberculosis prevalence survey. 2016.

21. Ncube, R. T., Takarinda, K. C., Zishiri, C., Van den Boogaard, W., Mlilo, N., Chiteve, C., Sandy C. Agestratified tuberculosis treatment outcomes in Zimbabwe: are we paying attention to the most vulnerable? Public Heal Action.

22. TisseraW(2003) Non compliance with anti tuberculosis treatment at Colombo Chest Clinic. NTI Bulletin 39, 5-9.

23. Vijay S, Balasangameswara VH, Jagannatha PS, Saroja VN \& Kumar P (2003) Defaults among TB patients treated under DOTS in Bangalore city: a search for solutions. Indian Journal of Tuberculosis 50, 185-195.

24. World Health Organization. Definitions and reporting framework for tuberculosis - 2013 revision. 2014.

25. World Health Organization. Gender and tuberculosis control: Towards a strategy for research and action. WHO/CDS/TB/2000.280

26. World Health Organization. Global Tuberculosis report. 2017;

27. World Health Organization. The END TB Strategy. 2014.

\section{Tables}

Table 1: Characteristics of TB patients treated from Kampala $2014-2016(n=17,461)$ 


\begin{tabular}{|c|c|c|c|c|c|c|}
\hline \multirow[b]{3}{*}{ Variables } & \multicolumn{6}{|c|}{ Sex } \\
\hline & \multicolumn{2}{|c|}{ Total } & \multicolumn{2}{|c|}{ Male } & \multicolumn{2}{|c|}{ Female } \\
\hline & Number & Percent & Number & Percent & Number & Percent \\
\hline \multicolumn{7}{|l|}{ Age category (Years) } \\
\hline $0-4$ & & 2.8 & & & & \\
\hline & 497 & & 270 & 2.5 & 227 & 3.4 \\
\hline $5-14$ & 525 & 3.0 & 265 & 2.4 & 260 & 3.9 \\
\hline $15-24$ & 3,538 & 20.3 & 1,890 & 17.4 & 1,648 & 25.0 \\
\hline $25-34$ & 6,125 & 35.1 & 3,766 & 34.6 & 2,359 & 35.8 \\
\hline $35-44$ & 3,991 & 22.9 & 2,771 & 25.5 & 1,220 & 18.5 \\
\hline $45-54$ & 1,880 & 10.8 & 1,312 & 12.1 & 568 & 8.6 \\
\hline $55-64$ & 586 & 3.4 & 405 & 3.7 & 181 & 2.7 \\
\hline $65+$ & 319 & 1.8 & 198 & 1.8 & 121 & 1.8 \\
\hline Health division & & & & & & \\
\hline Mulago national referral Hospital & 6832 & 39.1 & 4130 & 38.0 & 2702 & 41.0 \\
\hline Kawempe division & 1951 & 11.2 & 1164 & 10.7 & 787 & 12.0 \\
\hline Rubaga division & 2277 & 13.0 & 1405 & 12.9 & 872 & 13.2 \\
\hline Makindye division & 2162 & 12.4 & 1339 & 12.3 & 823 & 12.5 \\
\hline Nakawa division & 1572 & 9.0 & 1069 & 9.8 & 503 & 7.6 \\
\hline Central division & 2667 & 15.3 & 1770 & 16.3 & 897 & 13.6 \\
\hline Health Facility Ownership & & & & & & \\
\hline Government & 11297 & 64.7 & 7142 & 65.7 & 4155 & 63.1 \\
\hline Private Not For Profit & 4829 & 27.7 & 2933 & 27.0 & 1896 & 28.8 \\
\hline Private For Profit & 1335 & 7.6 & 802 & 7.4 & 533 & 8.1 \\
\hline $\begin{array}{l}\text { Health Facility Level of } \\
\text { Care }\end{array}$ & & & & & & \\
\hline National Referral Hospital & 7053 & 40.4 & 4278 & 39.3 & 2775 & 42.1 \\
\hline Regional Referral Hospital & 754 & 4.3 & 497 & 4.6 & 257 & 3.9 \\
\hline General Hospital & 3177 & 18.2 & 1999 & 18.4 & 1178 & 17.9 \\
\hline Health Centre IV & 1660 & 9.5 & 1134 & 10.4 & 526 & 8.0 \\
\hline Health Centre III & 4323 & 24.8 & 2673 & 24.6 & 1650 & 25.1 \\
\hline Health Centre II & 242 & 1.4 & 138 & 1.3 & 104 & 1.6 \\
\hline Clinic & 252 & 1.4 & 158 & 1.5 & 94 & 1.4 \\
\hline Type of Tuberculosis & & & & & & \\
\hline $\begin{array}{l}\text { Pulmonary Bacteriologically } \\
\text { Confirmed }\end{array}$ & 10418 & 59.7 & 6625 & 60.9 & 3793 & 57.6 \\
\hline Pulmonary Clinically diagnosed & 4053 & 23.2 & 2520 & 23.2 & 1533 & 23.3 \\
\hline Extra-Pulmonary & 2990 & 17.1 & 1732 & 15.9 & 1258 & 19.1 \\
\hline Type of TB patient & & & & & & \\
\hline New on TB treatment & 16154 & 92.5 & 9926 & 91.3 & 6228 & 94.6 \\
\hline Return after relapse & 885 & 5.1 & 633 & 5.8 & 252 & 3.8 \\
\hline $\begin{array}{l}\text { Return after lost to follow } \\
\text { up }\end{array}$ & 314 & 1.8 & 249 & 2.3 & 65 & 1.0 \\
\hline Return after Failure & 107 & 0.6 & 69 & 0.6 & 38 & 0.6 \\
\hline $\begin{array}{l}\text { Treatment History } \\
\text { Unknown }\end{array}$ & 1 & 0.0 & 0 & 0.0 & 1 & 0.0 \\
\hline
\end{tabular}




\section{HIV Status}

Positive

Negative

ART given

Yes

DOT status

Facility Based DOT

Community Based DOT

Not Recorded

$8540 \quad 48.9$

48.9

4951

45.5

3589

54.5

8921

5926

54.5

2995

45.5

Treatment outcomes

Cured

Treatment Completed

$7919 \quad 92$.

4597

92.8

3322

92.6

$621 \quad 7.3$

354

7.2

267

7.4

Died

Failure

Lost to Follow Up

\begin{tabular}{rrrrr}
411 & 2.4 & 309 & 2.8 & 102 \\
\hline 12448 & 71.3 & 7657 & 70.4 & 4791 \\
\hline 4602 & 26.4 & 2911 & 26.8 & 1691 \\
\hline 7879 & 45.1 & 4947 & 45.5 & 2932 \\
\hline 6611 & 37.9 & 4064 & 37.4 & 2547 \\
\hline 1867 & 10.7 & 1107 & 10.2 & 760 \\
\hline 166 & 1.0 & 109 & 1.0 & 57 \\
\hline 938 & 5.4 & 650 & 6.0 & 288
\end{tabular}

1.5

72.8

25.7

44.5

38.7

11.5

0.9

4.4

Table 2: A logistic regression of Treatment completion and patients factors by gender among TB patients, Kampala $2014-2016(\mathrm{n}=17,461)$ 


\begin{tabular}{|c|c|c|c|c|c|c|c|c|}
\hline & \multicolumn{4}{|c|}{ Male gender } & \multicolumn{4}{|c|}{ Female gender } \\
\hline & \multicolumn{2}{|c|}{ Univariate } & \multicolumn{2}{|c|}{ Multivariate } & \multicolumn{2}{|c|}{ Univariate } & \multicolumn{2}{|c|}{ Multivariate } \\
\hline & OR (95\% CI) & $\begin{array}{c}\text { P- } \\
\text { value }\end{array}$ & $\begin{array}{c}\text { Adjusted OR } \\
(95 \% \mathrm{CI})\end{array}$ & $\begin{array}{c}\text { P- } \\
\text { value }\end{array}$ & OR $(95 \% \mathrm{CI})$ & $\begin{array}{c}\text { P- } \\
\text { value }\end{array}$ & $\begin{array}{c}\text { Adjusted OR } \\
(95 \% \mathrm{CI})\end{array}$ & $\begin{array}{c}\mathrm{P}- \\
\text { value }\end{array}$ \\
\hline \multicolumn{9}{|c|}{ Age category (Ref $=0-4$ Years) } \\
\hline 5 - 14 Years & $\begin{array}{c}1.96(1.23- \\
3.13)\end{array}$ & 0.004 & $\begin{array}{c}2.02(1.26- \\
3.24)\end{array}$ & 0.003 & $\begin{array}{c}1.40(0.83- \\
2.36)\end{array}$ & 0.211 & $\begin{array}{c}1.33(0.78- \\
2.28)\end{array}$ & 0.297 \\
\hline 15 - 24 Years & $\begin{array}{c}2.34(1.69- \\
3.23)\end{array}$ & $<0.001$ & $\begin{array}{c}1.91(1.34- \\
2.71)\end{array}$ & $<0.001$ & $\begin{array}{l}1.27(0.86- \\
1.87)\end{array}$ & 0.230 & $\begin{array}{c}1.34(0.75- \\
1.74)\end{array}$ & 0.545 \\
\hline 25 - 34 Years & $\begin{array}{c}1.41(1.04- \\
1.90)\end{array}$ & 0.026 & $\begin{array}{c}1.39(1.00- \\
1.94)\end{array}$ & 0.047 & $\begin{array}{c}0.93(0.63- \\
1.35)\end{array}$ & 0.689 & $\begin{array}{c}1.15(0.76- \\
1.73)\end{array}$ & 0.514 \\
\hline 35 - 44 Years & $\begin{array}{c}1.23(0.91- \\
1.67)\end{array}$ & 0.181 & $\begin{array}{c}1.32(0.95- \\
1.84)\end{array}$ & 0.102 & $\begin{array}{l}0.78(0.53- \\
1.15)\end{array}$ & 0.210 & $\begin{array}{c}1.07(0.70- \\
1.63)\end{array}$ & 0.758 \\
\hline 45 - 54 Years & $\begin{array}{c}0.95(0.70- \\
1.31)\end{array}$ & 0.778 & $\begin{array}{c}1.03(0.73- \\
1 . .46)\end{array}$ & 0.845 & $\begin{array}{l}0.65(0.43- \\
0.97)\end{array}$ & 0.037 & $\begin{array}{c}0.83(0.53- \\
1.29)\end{array}$ & 0.401 \\
\hline 55 - 64 Years & $\begin{array}{c}1.05(0.72- \\
1.53)\end{array}$ & 0.004 & $\begin{array}{c}1.06(0.71- \\
1.58)\end{array}$ & 0.758 & $\begin{array}{l}0.49(0.30- \\
0.80)\end{array}$ & 0.004 & $\begin{array}{l}0.56(0.33- \\
0.94)\end{array}$ & 0.029 \\
\hline $65+$ Years & $\begin{array}{c}0.76(0.50- \\
1.17)\end{array}$ & 0.219 & $\begin{array}{c}0.69(0.44- \\
1.08)\end{array}$ & 0.107 & $\begin{array}{l}0.37(0.22- \\
0.62)\end{array}$ & $<0.001$ & $\begin{array}{l}0.33(0.19- \\
0.58)\end{array}$ & $<0.001$ \\
\hline \multicolumn{9}{|c|}{ Disease classification (Pulmonary Bacteriologically Confirmed) } \\
\hline $\begin{array}{l}\text { Pulmonary Clinically } \\
\text { diagnosed }\end{array}$ & $\begin{array}{c}0.61(0.55- \\
0.69)\end{array}$ & $<0.001$ & $\begin{array}{l}0.67(0.59- \\
0.76)\end{array}$ & $<0.001$ & $\begin{array}{l}0.60(0.52- \\
0.71)\end{array}$ & $<0.001$ & $\begin{array}{l}0.67(0.56- \\
0.79)\end{array}$ & $<0.001$ \\
\hline Extra-Pulmonary & $\begin{array}{c}0.54(0.47- \\
0.62)\end{array}$ & $<0.001$ & $\begin{array}{l}0.60(0.53- \\
0.69)\end{array}$ & $<0.001$ & $\begin{array}{l}0.46(0.39- \\
0.54)\end{array}$ & $<0.001$ & $\begin{array}{l}0.58(0.49- \\
0.69)\end{array}$ & $<0.001$ \\
\hline \multicolumn{9}{|c|}{ Patient type (Previously treated) } \\
\hline New patient & $\begin{array}{c}1.65(1.29- \\
2.13)\end{array}$ & $<0.001$ & $\begin{array}{c}1.58(1.34- \\
1.86)\end{array}$ & $<0.001$ & $\begin{array}{l}1.65(1.29- \\
2.13)\end{array}$ & $<0.001$ & $\begin{array}{l}1.65(1.27- \\
2.14)\end{array}$ & $<0.001$ \\
\hline \multicolumn{9}{|l|}{ HIV status (HIV Positive) } \\
\hline HIV Negative & $\begin{array}{c}1.86(1.68- \\
2.06)\end{array}$ & $<0.001$ & $\begin{array}{c}1.70(1.52- \\
1.90)\end{array}$ & $<0.001$ & $\begin{array}{l}2.61(2.26- \\
3.01)\end{array}$ & $<0.001$ & $\begin{array}{c}2.58(2.20- \\
3.02)\end{array}$ & $<0.001$ \\
\hline \multicolumn{9}{|c|}{ Health Facility Level of Care (National referral Hospital) } \\
\hline $\begin{array}{l}\text { Regional Referral } \\
\text { Hospital }\end{array}$ & $\begin{array}{c}1.22(0.96- \\
1.57)\end{array}$ & 0.107 & $\begin{array}{c}1.15(0.88- \\
1.50)\end{array}$ & 0.314 & $\begin{array}{l}1.65(1.14- \\
2.39)\end{array}$ & 0.007 & $\begin{array}{l}1.38(0.93- \\
2.06)\end{array}$ & 0.108 \\
\hline General Hospital & $\begin{array}{c}1.66(1.43- \\
1.93)\end{array}$ & $<0.001$ & $\begin{array}{l}1.71(1.46- \\
2.00)\end{array}$ & $<0.001$ & $\begin{array}{l}1.95(1.60- \\
2.38)\end{array}$ & $<0.001$ & $\begin{array}{l}1.89(1.53- \\
2.32)\end{array}$ & $<0.001$ \\
\hline Health Centre IV & $\begin{array}{c}1.42(1.19- \\
1.70)\end{array}$ & $<0.001$ & $\begin{array}{c}1.26(1.04- \\
1.51)\end{array}$ & 0.015 & $\begin{array}{l}1.99(1.50- \\
2.64)\end{array}$ & $<0.001$ & $\begin{array}{l}1.81(1.35- \\
2.42)\end{array}$ & $<0.001$ \\
\hline Health Centre III & $\begin{array}{c}1.22(1.08- \\
1.39)\end{array}$ & 0.002 & $\begin{array}{c}1.32(1.15 \\
-1.50)\end{array}$ & $<0.001$ & $\begin{array}{c}1.34(1.14- \\
1.57)\end{array}$ & $<0.001$ & $\begin{array}{c}1.52(1.28 \\
-1.80)\end{array}$ & $<0.001$ \\
\hline Health Centre II & $\begin{array}{c}1.18(0.76- \\
1.85)\end{array}$ & 0.461 & $\begin{array}{c}1.02(0.65- \\
1.61)\end{array}$ & 0.925 & $\begin{array}{c}1.33(0.79- \\
2.26)\end{array}$ & 0.284 & $\begin{array}{l}1.38(0.80- \\
2.38)\end{array}$ & 0.248 \\
\hline Clinic & $\begin{array}{c}1.46(0.93- \\
2.29)\end{array}$ & 0.097 & $\begin{array}{c}1.33(0.84- \\
2.11)\end{array}$ & 0.216 & $\begin{array}{c}2.19(1.13- \\
4.25)\end{array}$ & 0.020 & $\begin{array}{c}2.04(1.04- \\
4.01)\end{array}$ & 0.039 \\
\hline \multicolumn{9}{|c|}{ Health Facility ownership (Government) } \\
\hline Private not for profit & $\begin{array}{c}1.16(1.03- \\
1.30)\end{array}$ & 0.013 & & & $\begin{array}{c}1.28(1.10- \\
1.48)\end{array}$ & 0.001 & & \\
\hline Private for profit & $\begin{array}{c}1.50(1.21- \\
1.86)\end{array}$ & $<0.001$ & & & $\begin{array}{l}1.61(1.22- \\
2.11)\end{array}$ & 0.001 & & \\
\hline \multicolumn{9}{|c|}{ Directly Observed Therapy (Facility DOT) } \\
\hline Community Based DOT & $\begin{array}{c}0.90(0.65- \\
1.25)\end{array}$ & 0.542 & & & $\begin{array}{c}1.26(0.76- \\
2.09)\end{array}$ & 0.364 & & \\
\hline
\end{tabular}

\section{Annex 1: Operational Definition}


According to the standard definitions adopted from $\mathrm{WHO}$, the following clinical case and treatment outcome operational terms will be used:

\section{Pulmonary Bacteriologically Confirmed TB patient (P-BC)}

A patient with Genexpert sputum test results MTB detected or at least one sputum specimen which with positive for acid fast bacilli (AFB) by microscopy.

\section{Pulmonary Clinically Diagnosed TB patient (P-CD)}

A patient who does not fulfil the criteria for bacteriological confirmation but has been diagnosed with active TB by a clinician or other medical practitioner who has decided to give the patient a full course of TB treatment. This includes cases diagnosed on the basis of X-ray abnormalities or suggestive histology and Extra Pulmonary cases without laboratory confirmation.

\section{Extra Pulmonary TB patient (EPTB)}

This is a patient with TB in the organs other than the lungs, such as lymph nodes, abdomen, genitourinary tract, skin, joints and bones, the meninges and others.

According to $\mathrm{WHO}$, treatment outcomes were categorized into, successful treatment completion is if TB patient cured (negative smear microscopy at the end of treatment and on at least one previous follow-up test) or completed treatment with resolution of symptoms.

Unsuccessful treatment completion on the other hand is if treatment resulted in treatment failure (remaining smear-positive after 5 months of treatment), getting lost to follow up (patients who interrupted their treatment for two consecutive months or more after registration), or died. 